\title{
Bilateral inferior petrosal sinus sampling in the diagnosis of Cushing disease
}

\author{
This article was published in the following Dove Press journal: \\ Journal of Vascular Diagnostics \\ 16 April 2015 \\ Number of times this article has been viewed
}

\author{
Amy R Deipolyi' \\ Rahmi Oklu² \\ 'Vascular and Interventional \\ Radiology, NYU Langone Medical \\ Center, New York, NY, USA; ${ }^{2}$ Division \\ of Vascular and Interventional \\ Radiology, Massachusetts General \\ Hospital, Harvard Medical School, \\ Boston, MA, USA
}

\begin{abstract}
Bilateral inferior petrosal sinus sampling (BIPSS) is a minimally invasive procedure performed in the workup of adrenocorticotropic hormone (ACTH)-dependent Cushing syndrome (CS). Because noninvasive tests in the evaluation of CS patients lack sensitivity, BIPSS is the gold standard in diagnosing Cushing disease (CD), which is a pituitary source of excess ACTH. Here, the pathophysiology of CD and procedural details of BIPSS are reviewed.

Keywords: pituitary adenoma, Cushing disease, inferior petrosal sinus, venous sampling

\section{Introduction}

Cushing syndrome (CS) carries an increased morbidity and mortality ${ }^{1}$ with an estimated incidence of one per 500,000 persons. $^{2}$ Most cases of endogenous CS are caused by Cushing disease (CD), characterized by an adrenocorticotropic hormone (ACTH)secreting pituitary adenoma that may be surgically resected for a cure. Noninvasive imaging and laboratory tests have low sensitivity, confounding diagnosis. Bilateral inferior petrosal sinus sampling (BIPSS) is sensitive and specific, and is therefore the gold standard assay for diagnosing $\mathrm{CD} .^{3}$
\end{abstract}

\section{Pathophysiology of Cushing disease}

$\mathrm{CS}$ is an endocrine disorder involving the hypothalamus-pituitary-adrenal axis (HPAA), leading to excess cortisol (Figure 1). Symptoms include central obesity, moon facies, and proximal muscle weakness, dermatologic changes, including thin skin, purple striae, baldness, and hirsutism, and metabolic derangements, including hypertension, hyperglycemia, menstrual irregularities, and impotence. ${ }^{4}$

In the normally functioning HPAA, the hypothalamus secretes corticotropinreleasing hormone $(\mathrm{CRH})$, which stimulates the anterior pituitary to secrete ACTH. ACTH in turn stimulates adrenal cortical secretion of cortisol. Hypothalamic secretion of arginine vasopressin (AVP) also stimulates anterior pituitary secretion of ACTH. By a negative feedback loop, cortisol inhibits pituitary secretion of ACTH and hypothalamic secretion of CRH. In the case of an ACTH-secreting pituitary adenoma, ACTH is secreted without hormonal stimulation. Therefore, despite negative feedback loops triggered by excess cortisol, ACTH is autonomously secreted, further increasing cortisol levels, leading to Cushingoid signs and symptoms.

Recent progress has uncovered potential pathways underlying increased ACTH section and corticotroph tumorigenesis. Synthesis of proopiomelanocortin (Pomc), the precursor of $\mathrm{ACTH}$, is upregulated by an epidermal growth factor receptor
Correspondence: Rahmi Oklu Division of Vascular and Interventional Radiology, Massachusetts General Hospital, Harvard Medical School, 55 Fruit Street, 290 Gray/Bigelow, Boston, MA 02114 , USA

Tel + I 6176436315

Email roklu@mgh.harvard.edu submit your manuscript | www.dovepress.com

Dovepress

http://dx.doi.org// 0.2/47/JVD.S79252
Journal of Vascular Diagnostics 20 I5:3 I-7 \section{I}

(c) (i) (-) 2015 Deipolyi and Oklu. This work is published by Dove Medical Press Limited, and licensed under Creative Commons Attribution - Non Commercial (unported, v3.0) License. The full terms of the License are available at http://creativecommons.org/licenses/by-n/3.0/. Non-commercial uses of the work are permitted without any further permission from Dove Medical Press Limited, provided the work is properly attributed. Permissions beyond the scope of the License are administered by Dove Medical Press Limited. Information on
how to request permission may be found at: http://www.dovepress.com/permissions.php 


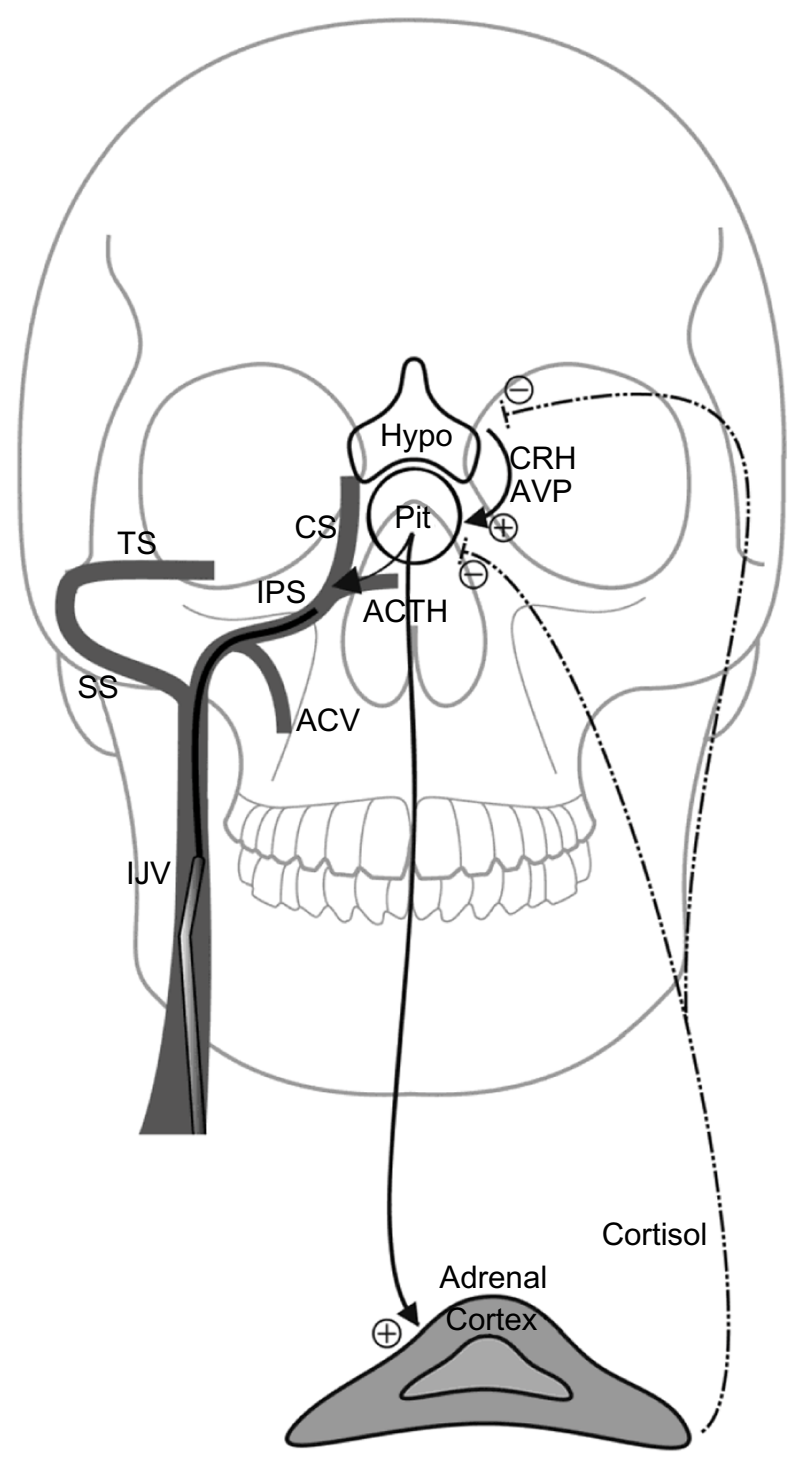

Figure I Anatomy and physiology of HPAA.

Notes: Hypothalamic (Hypo) secretion of $\mathrm{CRH}$ and AVP induce pituitary (Pit) secretion of ACTH. ACTH stimulates adrenal cortical secretion of cortisol, which in turn negatively modulates $\mathrm{CRH}$ and $\mathrm{ACTH}$ secretion. Pituitary secretion of ACTH is measured in the IPS. The ACV usually drains into the IPS before venous blood returns to the IJV. The IPS is accessed with a microcatheter (black tube), which is advanced via a five-French guiding catheter (gray tube) in the IJV. (+) indicates stimulatory pathway; $(-)$ indicates inhibitory pathway.

Abbreviations: HPAA, hypothalamus-pituitary-adrenal axis; $\mathrm{CRH}$, corticotropinreleasing hormone; AVP, arginine vasopressin; ACTH, adrenocorticotropic hormone; IPS, inferior petrosal sinus; ACV, anterior condylar vein; IJV, internal jugular vein; TS, transverse sinus; SS, sigmoid sinus; CS, cavernous sinus.

(EGFR) pathway. ${ }^{5}$ Recently, USP8 mutations, present in a third of corticotroph adenomas in the setting of CD, have been shown to increase EGFR levels, in turn stimulating Pomc and consequently ACTH levels. ${ }^{6}$ Such important investigation not only elucidates the pathogenesis of CD, but also suggests possible therapeutic and diagnostic strategies.

The pituitary gland is drained by hypophyseal veins that empty into a plexiform venous network overlying the pituitary surface, in turn draining laterally into the intercavernous and cavernous sinuses. Despite broad intercavernous communication, pituitary venous drainage is often unilateral, necessitating bilateral venous sampling to avoid false negatives. ${ }^{7}$ The cavernous sinus empties into the superior petrosal sinus posteriorly and superiorly, and the inferior petrosal sinus (IPS) posteriorly and inferiorly. The IPS in turn empties into the internal jugular vein after passing through the anterior jugular foramen. The IPS usually joins the internal jugular vein at the inferior jugular foramen margin, about $6 \mathrm{~mm}$ below its foraminal entry, though there is interperson variability. The diameter of the IPS is $2-4 \mathrm{~mm}$ within the jugular foramen. ${ }^{8}$

The IPS is the vein most proximal to the pituitary gland that can safely accommodate a microcatheter for venous sampling and measurement of pituitary ACTH secretion. Here, dilution due to contribution from other veins, such as the anterior condylar vein (ACV), is minimized.

The purpose of sampling the IPS is to identify a pituitary source of excess ACTH to diagnose CD. While CS is most often caused by exogenous glucocorticoid administration, endogenous CS may be due to ACTH- or cortisol-secreting tumors (Table 1). ${ }^{9,10}$ Most endogenous CS cases are caused by an ACTH-secreting pituitary adenoma (CD).

\section{Noninvasive workup}

Patients with suspected CS are first evaluated to diagnose hypercortisolemia, with laboratory tests, including urinary free cortisol, late-night salivary cortisol, and the low-dose dexamethasone suppression test (Figure 2). ${ }^{11}$

Once hypercortisolemia has been established, the next step is to identify the cause. First, plasma ACTH levels are measured. ${ }^{12}$ Low ACTH levels suggest ACTH-independent $\mathrm{CS}$; abdominal cross-sectional imaging may reveal an adrenal cause of excess cortisol secretion. High or normal plasma ACTH suggests ACTH-dependent CS, and may be due to pituitary etiologies (hormone-secreting adenomas), or due to ectopic sources (gastrinomas, carcinoid and neuroendocrine tumors, pheochromocytoma, medullary thyroid

Table I Endogenous causes of CS

\begin{tabular}{ll}
\hline ACTH-dependent & \\
Ectopic source & $10 \%$ \\
Pituitary source (CD) & $67 \%$ \\
ACTH-independent & \\
Other & $2 \%$ \\
Adrenal carcinoma & $7 \%$ \\
Adrenal adenoma & $13 \%$ \\
\hline
\end{tabular}

Notes: Data from Boscaro and Arnaldi; ${ }^{9}$ and Nieman. ${ }^{10}$

Abbreviations: CS, Cushing syndrome; $\mathrm{ACTH}$, adrenocorticotropic hormone; $\mathrm{CD}$, Cushing disease. 


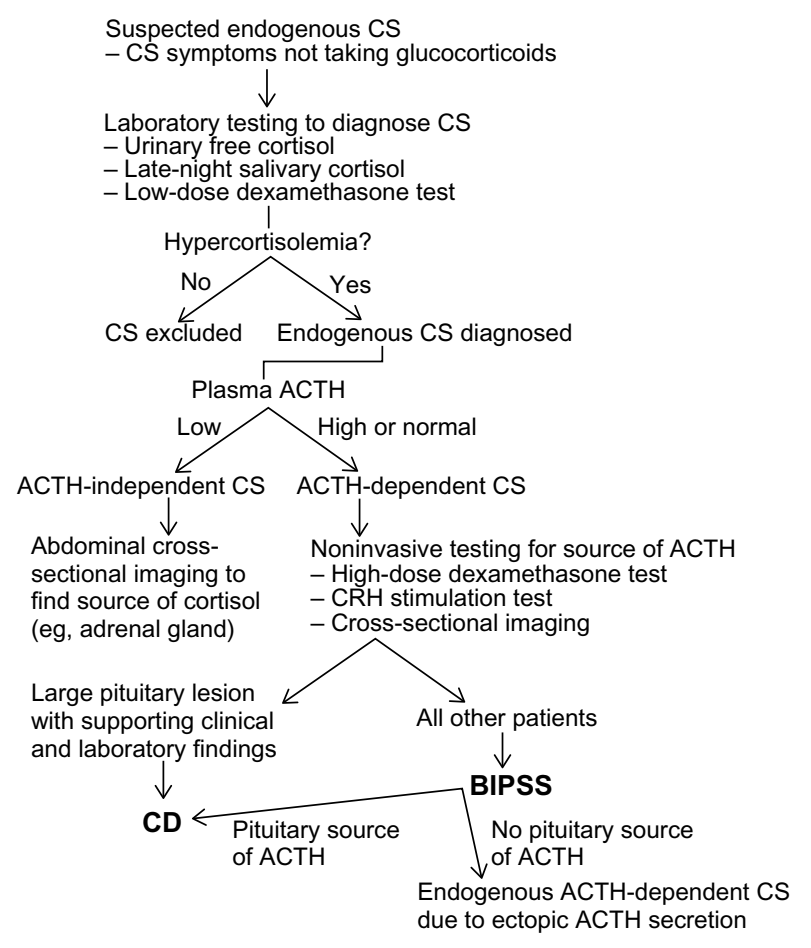

Figure 2 Workup of patients with suspected CD.

Abbreviations: CD, Cushing disease; CS, Cushing syndrome; $A C T H$, adrenocorticotropic hormone; BIPSS, bilateral inferior petrosal sinus sampling.

carcinoma, pancreatic carcinoma, and bronchioloalveolar carcinoma). ${ }^{13,14}$

Pituitary and ectopic ACTH secretion can be distinguished by noninvasive laboratory assays - the $\mathrm{CRH}$ stimulation test, the high-dose dexamethasone suppression test, and crosssectional imaging. ${ }^{12}$ The high-dose dexamethasone suppression test is the primary noninvasive diagnostic test; high-dose dexamethasone inhibits pituitary adenoma secretion of ACTH but does not usually inhibit ectopic ACTH sources of ACTH. However, sensitivity and specificity are only $60 \%-80 \%$. $^{11,15}$ The CRH stimulation test involves administering $\mathrm{CRH}$, which induces most pituitary tumors to increase ACTH secretion, in turn upregulating cortisol levels that are measured peripherally. However, many ectopic ACTH-secreting tumors also respond to $\mathrm{CRH}$; hence, this test cannot necessarily distinguish pituitary and ectopic sources. ${ }^{16}$

Pituitary gadolinium-enhanced MRI, which is superior to $\mathrm{CT}$, is performed for patients with ACTH-dependent $\mathrm{CS}$, and can have sensitivity of roughly $80 \% .^{11,17,18}$ However, because of the high prevalence (10\%-20\%) of nonfunctioning pituitary incidentalomas, ${ }^{19-21}$ the finding of a pituitary lesion does not definitively diagnose CD. Furthermore, microadenomas may be too small to detect by imaging, leading to false negatives. ${ }^{21}$ Only large lesions $(>6 \mathrm{~mm})$ on MRI with supporting clinical symptomatology and laboratory confirmation can be considered diagnostic of CD. ${ }^{12}$ In all other cases, BIPSS with CRH stimulation is indicated for further evaluation. ${ }^{22}$

\section{BIPSS procedure}

Most often, BIPSS is performed by sampling ACTH peripherally and from both IPSs before and after CRH (Acthrel; Ben Venue Laboratories, Ohio, USA) administration. In the $\mathrm{US}, \mathrm{CRH}$ is typically given at a dose of $1 \mu \mathrm{g} / \mathrm{kg}$, by slow intravenous push over 30 seconds; in other countries, a typical dose is $100 \mu \mathrm{g}$. Conscious sedation is preferred to allow for the monitoring of symptoms suggesting complications. A 6-French sheath is advanced into the right femoral vein, and a five-French sheath into the left femoral vein. The larger sheath allows for sampling from the common femoral vein, while a 5-French catheter is in place distally. Subsequently, 3,000-5,000 units of heparin are given to prevent cavernous sinus and other venous thrombosis.

Next, 5-French Davis catheters are advanced through each femoral vein sheath into the contralateral internal jugular vein, followed by 2.8 -French microcatheters, directed medially at the C1-2 level to access the orifice of the IPS ${ }^{14}$ without entering clival veins. ${ }^{7}$ Both catheters are positioned symmetrically.

Once catheter positions are confirmed, two baseline ACTH specimens are collected from the right femoral sheath (peripheral specimen) and both IPSs. CRH is then administered peripherally. Repeat ACTH sampling from the periphery and both IPSs is obtained 3 minutes, 5 minutes, 10 minutes, and 15 minutes after the injection of $\mathrm{CRH}$. Samples are collected in tubes that are placed on ice before transport to the laboratory. Upon completion of sampling, both femoral sheaths are removed, and manual compression is used to obtain hemostasis before transferring patients to the recovery room for a rest of approximately 4 hours. In our experience, groin hematoma occurs rarely, and thus protamine is not routinely administered. ${ }^{23,24}$

In experienced centers, BIPSS sensitivity and specificity approach $100 \%,{ }^{25}$ particularly when $\mathrm{CRH}$ administration is incorporated. ${ }^{26}$

\section{BIPSS results interpretation}

Interpreting BIPSS results involves calculating the ratio of IPS to peripheral (IPS/P) ACTH levels assessed (Table 2). The diagnosis of CD is confirmed by a baseline IPS/P $\geq 2$ or CRH-stimulated IPS/P $\geq 3 .{ }^{22}$

Some researchers have tried to extrapolate lesion lateralization from the results, by calculating an intersinus ACTH 
Table 2 Example of BIPSS results

\begin{tabular}{|c|c|c|c|c|c|}
\hline$\overline{\text { Time }}$ & Baseline & 3 minutes & 5 minutes & 10 minutes & 15 minutes \\
\hline Peripheral & 30 & 45 & 72 & 160 & 189 \\
\hline Left & 92 & 531 & $\mathrm{I}, 255$ & 1,732 & $\mathrm{I}, 349$ \\
\hline Right & 165 & 753 & 3,640 & 4,250 & 1,903 \\
\hline Left IPS/P & 3.1 & 11.8 & 17.4 & 10.8 & 7.1 \\
\hline Right IPS/P & 5.5 & 16.7 & 50.6 & 26.6 & 10.1 \\
\hline
\end{tabular}

Notes: ACTH levels (pg/mL) assessed from the left and right IPS, and a peripheral vein (right common femoral) at baseline and various time points after CRH administration are presented. This patient had a pathology-proven right pituitary ACTH-secreting adenoma causing CD. The IPS/P ratio is calculated as the ACTH value from the IPS divided by the value from the peripheral vein; $C D$ is confirmed by baseline IPS/P $\geq 2$ or $C R H$-stimulated IPS/P $\geq 3$.

Abbreviations: BIPSS, bilateral inferior petrosal sinus sampling; IPS/P, inferior petrosal sinus/peripheral; ACTH, adrenocorticotropic hormone; $C R H$, corticotropin-releasing hormone; $C D$, Cushing disease.

ratio, taking ratios $\geq 1.4$ as an evidence of ipsilateral adenoma localization. However, reported accuracy, with surgical findings as the gold standard, ranges from $50 \%$ to $100 \%{ }^{25}$ Thus, full surgical exploration of the entire pituitary gland is commonly performed in lieu of hemihypophysectomy, regardless of lateralization suggested by BIPSS.

\section{BIPSS procedure pearls}

\section{Assuring adequate catheter positioning}

As the goal of BIPSS is to sample venous outflow from the pituitary gland in the vein most proximal to the gland but without a risk of complication, the microcatheter should be advanced beyond the junction with ACV to prevent sample dilution. Catheterization that is too central should be avoided; because the jugular fossa periosteum is highly sensitive, high catheterizations will cause otalgia, which can be assessed symptomatically as long as the patient is sedated but not intubated. ${ }^{7}$ Hand injections are used to delineate venous anatomy and demonstrate adequate positioning, obtained when ipsilateral IPS filling is seen with contralateral reflux (Figure 3$).^{7}$ Once the catheters are in place and sampling begins, intermittent fluoroscopy should be performed to assure the catheters remain positioned throughout.

\section{Variant anatomies of IPS-internal jugular venous junction}

An assessment of venous anatomy may reveal variants that influence result interpretation. ${ }^{27,28}$ In many (45\%) people, the IPS empties in the internal jugular vein without significant contribution from the ACV. In other patients (25\%), there is an anastomosis of the IPS with the ACV before joining the internal jugular vein, while in others $(25 \%)$, the IPS joins the internal jugular vein as a plexus of veins, rather than a single vein (Figure 4). Specimens may be diluted by ACV contribution, and noting such an anastomosis with the IPS should prompt catheterization more centrally to avoid dilution. Least commonly $(1 \%-5 \%)$, the IPS empties primarily through the
ACV into the vertebral venous plexus. ${ }^{8,29}$ In this scenario, the IPS may not be amenable to catheterization, precluding sampling. Delineating the venous anatomy is therefore essential to performing successful BIPSS.

\section{Avoiding complications}

In the hands of an experienced interventional radiologist, BIPSS is a safe procedure with few complications. Groin hematoma from femoral access is the most common complication, seen in fewer than $5 \%$ of patients, ${ }^{8}$ similar to other procedures requiring common femoral venous access. ${ }^{30}$ Very rarely, serious complications have been reported, including brainstem hemorrhages or nonhemorrhagic brainstem infarctions. ${ }^{8,31}$ These constitute only one or two cases of hundreds of sampling procedures, obscuring the cause of such adverse events, which could be related to catheter choice, for example.
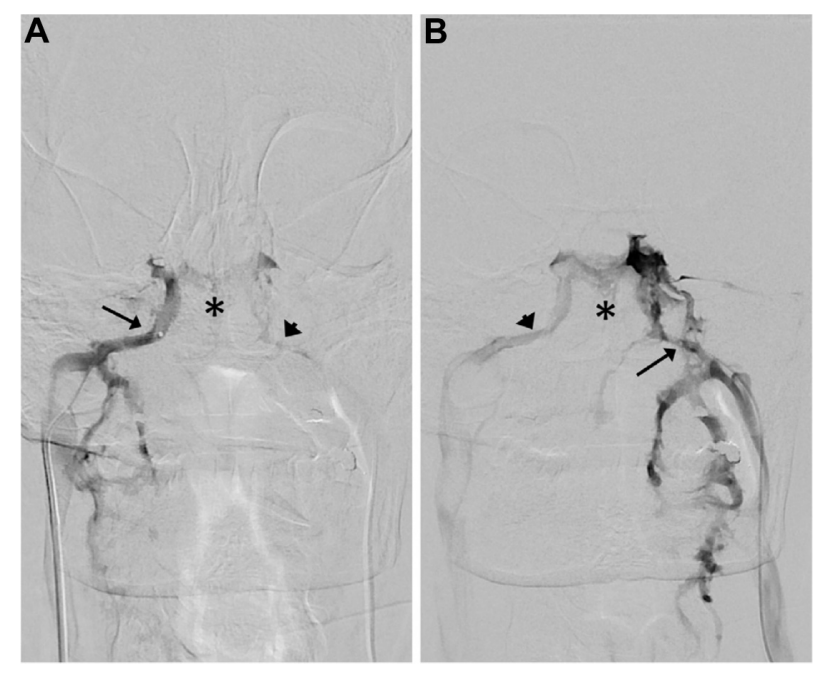

Figure 3 Digital subtraction angiography views of the IPSs.

Notes: (A) Black arrow indicates the position of the right microcatheter within the IPS. Contrast injection demonstrates opacification of the cavernous sinus and the contralateral IPS (arrow head); (B) Black arrow indicates the position of the left microcatheter within the IPS. Contrast injection demonstrates opacification of the cavernous sinus and the contralateral IPS (arrowhead). Black star indicates the expected position of the pituitary gland.

Abbreviation: IPS, inferior petrosal sinus. 

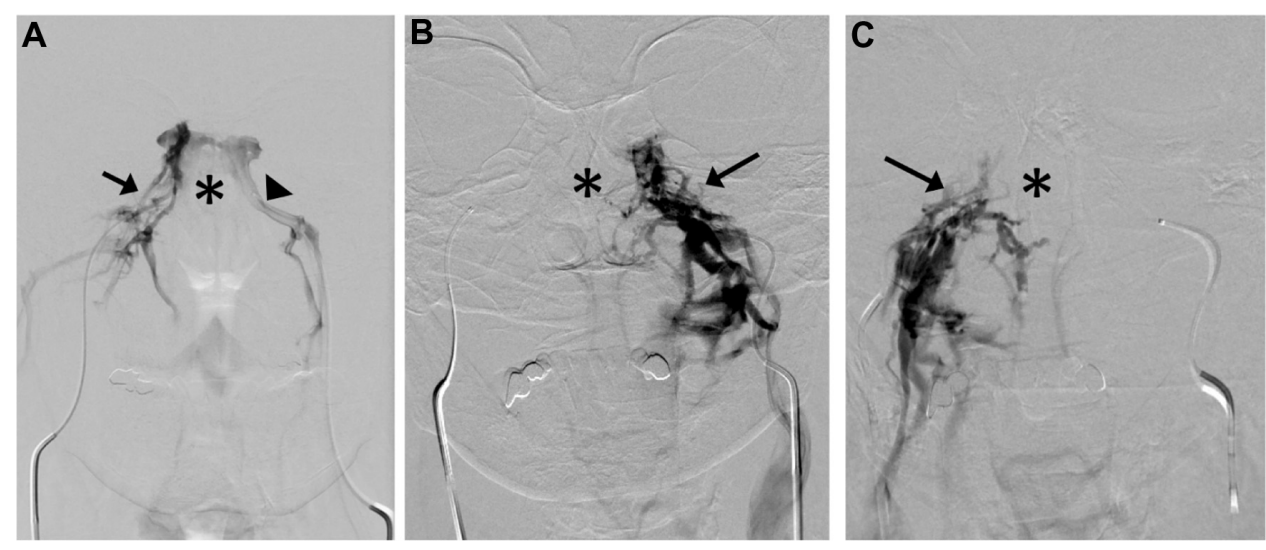

Figure 4 Variant IPS anatomy in digital subtraction angiography.

Notes: (A) The left IPS (arrowhead) is a single vein as demonstrated by reflux from contralateral IPS contrast injection. The arrow indicates at least three right-sided IPS veins. Contrast injection from the presumed (B) left and (C) the right IPSs reveal a plexus of veins (arrows). (A-C) *indicates the expected location of the pituitary gland.

Abbreviation: IPS, inferior petrosal sinus.

Occasionally, thromboembolic events occur, as may be expected in the hypercoagulable state of CS. These primarily include cavernous sinus thrombosis, and deep venous thrombosis potentially leading to pulmonary embolism..$^{32-34}$ Routine heparinization is an essential step to avoiding thromboembolic complications, and venous thrombosis will almost never be encountered if such measures are taken.

\section{Newer techniques improving diagnostic accuracy and reducing complications}

Because of reported false negative rate ranging from $1 \%$ to $10 \%$, efforts have been made to increase the certainty of diagnosis of ectopic sources of ACTH, when a pituitary source is not identified during BIPSS. Specifically, prolactin levels in the collected venous specimen is considered to accurately demonstrate that the sample is truly from the pituitary venous effluent. ${ }^{35}$ While some studies suggest that prolactin may be used to demonstrate correct catheter positioning and to normalize measured ACTH levels, ${ }^{36}$ because of the high cost of the assay, samples are stored until ACTH results are received, and only used if results indicate an ectopic source. Such samples can then be assessed for prolactin to confirm the adequacy of sampling and prevent false negative outcomes. ${ }^{37-39}$

The primary technological advance enabling correct catheter positioning and reducing complications is the incorporation of microcatheters, which became more commonly used in the $1990 \mathrm{~s} .{ }^{40}$ Such devices allow for more central catheterization of the IPS, and likely have lower rates of venous thrombosis.

\section{Hormonal stimulation with desmopressin}

Because CRH is not always available, some researchers have used desmopressin (DDAVP, a synthetic analog of vasopressin) in its place to stimulate the pituitary during BIPSS, given at a dose of $10 \mu \mathrm{g}$ intravenously. Several small series suggest that this alternative may be safe and effective. ${ }^{22}$ In a series of 18 patients who underwent BIPSS with DDAVP, the procedure produced similar laboratory findings compared with sampling with CRH stimulation, and the sensitivity was 95\%. ${ }^{24}$ Because of its low cost compared with CRH, DDAVP administration may become routine in the future; however, larger series verifying its safety and efficacy are pending.

\section{Conclusion}

$\mathrm{CD}$ is a rare endocrine disease characterized by hypercortisolemia caused by excess ACTH secreted by the pituitary. Distinguishing pituitary sources from the ectopic sources of ACTH is challenging because of the limited accuracy of noninvasive assays. BIPSS is the gold standard diagnostic test with sensitivity and specificity of nearly $100 \%$. Understanding venous anatomical variation, intraprocedural heparinization, and attending to optimal catheter positioning and sample handling are all essential aspects to maximizing procedural safety and technical success.

Though BIPSS is more accurate than other diagnostic tests, it is not used as frequently as one might argue it should be due to its invasiveness and cost. However, it is generally agreed that BIPSS is indicated for ACTH-dependent hypercortisolemia ${ }^{14,22}$ and when noninvasive assays yield equivocal results. ${ }^{9}{ }^{92,22}$ Because of the high prevalence of pituitary incidentalomas, some institutions routinely perform BIPSS for all patients evaluated for CD. ${ }^{41}$ It is imperative for interventional radiologists to reach out to referring providers caring for patients with possible CD to optimize care for these patients. 


\section{Disclosure}

The authors report no conflicts of interest in this work.

\section{References}

1. Lindholm J, Juul S, Jørgensen JO, et al. Incidence and late prognosis of Cushing's syndrome: a population-based study. J Clin Endocrinol Metab. 2001;86(1):117-123.

2. Ross NS. Epidemiology of Cushing's syndrome and subclinical disease. Endocrinol Metab Clin North Am. 1994;23(3):539-546.

3. Lad SP, Patil CG, Laws ER Jr, Katznelson L. The role of inferior petrosal sinus sampling in the diagnostic localization of Cushing's disease. Neurosurg Focus. 2007;23(3):E2.

4. Cotran RS, Kumar V, Collins T. Robbins Pathologic Basis of Disease. 6 ed. Philadelphia: W.B. Saunders Company; 1999.

5. Fukuoka H, Cooper O, Ben-Shlomo A, et al. EGFR as a therapeutic target for human, canine, and mouse ACTH-secreting pituitary adenomas. J Clin Invest. 2011;121(12):4712-4721.

6. Reincke M, Sbiera S, Hayakawa A, et al. Mutations in the deubiquitinase gene USP8 cause Cushing's disease. Nat Genet. 2015;47(1): 31-38.

7. Doppman JL, Oldfield E, Krudy AG, et al. Petrosal sinus sampling for Cushing syndrome: anatomical and technical considerations. Work in progress. Radiology. 1984;150(1):99-103.

8. Miller DL, Doppman JL. Petrosal sinus sampling: technique and rationale. Radiology. 1991;178(1):37-47.

9. Boscaro M, Arnaldi G. Approach to the patient with possible Cushing's syndrome. J Clin Endocrinol Metab. 2009;94(9):3121-3131.

10. Nieman L. Causes and pathophysiology of Cushing's syndrome. In: Basow DS, editor. UpToDate. Waltham, MA: Epub 2011.

11. Arnaldi G, Angeli A, Atkinson AB, et al. Diagnosis and complications of Cushing's syndrome: a consensus statement. J Clin Endocrinol Metab. 2003;88(12):5593-5602.

12. Gross BA, Mindea SA, Pick AJ, Chandler JP, Batjer HH. Diagnostic approach to Cushing disease. Neurosurg Focus. 2007;23(3):E1.

13. Raff H, Sharma ST, Nieman LK. Physiological basis for the etiology, diagnosis, and treatment of adrenal disorders: Cushing's syndrome, adrenal insufficiency, and congenital adrenal hyperplasia. Compr Physiol. 2014;4(2):739-769.

14. Tomycz ND, Horowitz MB. Inferior petrosal sinus sampling in the diagnosis of sellar neuropathology. Neurosurg Clin N Am. 2009;20(3): 361-367.

15. Aron DC, Raff H, Findling JW. Effectiveness versus efficacy: the limited value in clinical practice of high dose dexamethasone suppression testing in the differential diagnosis of adrenocorticotropindependent Cushing's syndrome. J Clin Endocrinol Metab. 1997;82(6): 1780-1785.

16. Nieman L, Lacroix A, Martin K. Establishing the cause of Cushing's syndrome. In: Basow DS, editor. UpToDate. Waltham, MA: UpToDate; Epub 2011.

17. Escourolle H, Abecassis JP, Bertagna X, et al. Comparison of computerized tomography and magnetic resonance imaging for the examination of the pituitary gland in patients with Cushing's disease. Clin Endocrinol (Oxf). 1993;39(3):307-313.

18. Patronas N, Bulakbasi N, Stratakis CA, et al. Spoiled gradient recalled acquisition in the steady state technique is superior to conventional postcontrast spin echo technique for magnetic resonance imaging detection of adrenocorticotropin-secreting pituitary tumors. J Clin Endocrinol Metab. 2003;88(4):1565-1569.

19. Ezzat S, Asa SL, Couldwell WT, et al. The prevalence of pituitary adenomas: a systematic review. Cancer. 2004;101(3):613-619.

20. Hall WA, Luciano MG, Doppman JL, Patronas NJ, Oldfield EH. Pituitary magnetic resonance imaging in normal human volunteers: occult adenomas in the general population. Ann Intern Med. 1994; 120(10):817-820.
21. Molitch ME, Russell EJ. The pituitary "incidentaloma". Ann Intern Med. 1990;112(12):925-931.

22. Javorsky BR, Findling JW. Inferior petrosal sampling for the differential diagnosis of ACTH-dependent Cushing's syndrome. In: Bronstein MD, editor. Cushing's Syndrome: Pathophysiology, Diagnosis and Treatment. 1 ed. New York: Humana Press; 2010:105.

23. Deipolyi AR, Alexander B, Oklu R. Bilateral inferior petrosal sinus sampling: clinical experience in 327 patients. J of Vasc Interv Radiol. 2014;25(3):S64

24. Deipolyi AR, Alexander B, Rho J, Hirsch JA, Oklu R. Bilateral inferior petrosal sinus sampling using desmopressin or corticotropic-releasing hormone: a single-center experience. J Neurointerv Surg. Epub 2014.

25. Newell-Price J, Trainer P, Besser M, Grossman A. The diagnosis and differential diagnosis of Cushing's syndrome and pseudo-Cushing's states. Endocr Rev. 1998;19(5):647-672.

26. Oldfield EH, Doppman JL, Nieman LK, et al. Petrosal sinus sampling with and without corticotropin-releasing hormone for the differential diagnosis of Cushing's syndrome. N Engl J Med. 1991;325(13): 897-905.

27. Doppman JL, Chang R, Oldfield EH, Chrousos G, Stratakis CA, Nieman LK. The hypoplastic inferior petrosal sinus: a potential source of false-negative results in petrosal sampling for Cushing's disease. J Clin Endocrinol Metab. 1999;84(2):533-540.

28. Mamelak AN, Dowd CF, Tyrrell JB, McDonald JF, Wilson CB. Venous angiography is needed to interpret inferior petrosal sinus and cavernous sinus sampling data for lateralizing adrenocorticotropin-secreting adenomas. J Clin Endocrinol Metab. 1996;81(2):475-481.

29. Shiu PC, Hanafee WN, Wilson GH, Rand RW. Cavernous sinus venography. Am J Roentgenol Radium Ther Nucl Med. 1968;104(1): $57-62$.

30. Gunn AJ, Iqbal SI, Kalva SP, et al. Intravascular ultrasound-guided inferior vena cava filter placement using a single-puncture technique in 99 patients. Vasc Endovascular Surg. 2013;47(2):97-101.

31. Gandhi CD, Meyer SA, Patel AB, Johnson DM, Post KD. Neurologic complications of inferior petrosal sinus sampling. AJNR Am J Neuroradiol. 2008;29(4):760-765.

32. Blevins LS Jr, Clark RV, Owens DS. Thromboembolic complications after inferior petrosal sinus sampling in patients with Cushing's syndrome. Endocr Pract. 1998;4(6):365-367.

33. Bonelli FS, Huston J 3rd, Meyer FB, Carpenter PC. Venous subarachnoid hemorrhage after inferior petrosal sinus sampling for adrenocorticotropic hormone. AJNR Am J Neuroradiol. 1999;20(2): 306-307.

34. Obuobie K, Davies JS, Ogunko A, Scanlon MF. Venous thromboembolism following inferior petrosal sinus sampling in Cushing's disease. J Endocrinol Invest. 2000;23(8):542-544.

35. Findling JW, Kehoe ME, Raff H. Identification of patients with Cushing's disease with negative pituitary adrenocorticotropin gradients during inferior petrosal sinus sampling: prolactin as an index of pituitary venous effluent. J Clin Endocrinol Metab. 2004;89(12): 6005-6009.

36. Sharma ST, Nieman LK. Is prolactin measurement of value during inferior petrosal sinus sampling in patients with adrenocorticotropic hormone-dependent Cushing's syndrome? J Endocrinol Invest. 2013; 36(11):1112-1116.

37. Mulligan GB, Eray E, Faiman C, et al. Reduction of false-negative results in inferior petrosal sinus sampling with simultaneous prolactin and corticotropin measurement. Endocr Pract. 2014;17(1):33-40.

38. Sharma ST, Raff H, Nieman LK. Prolactin as a marker of successful catheterization during IPSS in patients with ACTH-dependent Cushing's syndrome. J Clin Endocrinol Metab. 2011;96(12): 3687-3694.

39. Daousi C, Nixon T, Javadpour M, Hayden K, MacFarlane IA. Inferior petrosal sinus ACTH and prolactin responses to CRH in ACTHdependent Cushing's syndrome: a single centre experience from the United Kingdom. Pituitary. 2010;13(2):95-104. 
40. Yagyu Y, Tsurusaki M, Kamiyama K, Kitagaki H, Murakami T. Feasible and technical aspects of transcatheter arterial chemoembolization for non-resectable hepatocellular carcinoma using a 3.5-French catheter system. Abdom Imaging. 2014;39(6):1304-1308.
41. Kaltsas GA, Giannulis MG, Newell-Price JD, et al. A critical analysis of the value of simultaneous inferior petrosal sinus sampling in Cushing's disease and the occult ectopic adrenocorticotropin syndrome. J Clin Endocrinol Metab. 1999;84(2):487-492.

\section{Publish your work in this journal}

Journal of Vascular Diagnostics is an international, peer-reviewed journal of diagnostics, focusing on non invasive vascular investigation methods involved in the evaluation of vascular diseases. The journal is committed to the rapid publication in the fields of vascular diseases. Original research, review, case reports, expert opinion and commentaries

\section{Dovepress}

are all considered for publication. The manuscript management system is completely online and includes a very quick and fair peer-review system, which is all easy to use. Visit http://www.dovepress.com/ testimonials.php to read real quotes from published authors.

Submit your manuscript here: http://www.dovepress.com/journal-of-vascular-diagnostics-journal 